\title{
DEFORMASYON HIZININ DP600 VE DP780 SAC MALZEMELERİN MEKANİK ÖZELLIKLERİNE VE DERİN ÇEKME İŞLEMİNE ETKİLERİNİN İNCELENMESİ
}

\author{
Onur ÇAVUŞOĞLU, Hakan GÜRÜN \\ Gazi Üniversitesi, Teknoloji Fakültesi, İmalat Mühendisliği, Ankara / TÜRKIYE \\ onurcavusoglu@gazi.edu.tr hgurun@gazi.edu.tr
}

(Geliş/Received: 28.11.2013; Kabul/Accepted: 06.11.2014)

ÖZET

Bu çalışmada, otomotiv endüstrisinde yaygın olarak kullanılan DP600 ve DP780 sac malzemelerin derin çekme işleminde deformasyon hızının etkileri incelenmiştir. Bu amaçla, farklı deformasyon hızlarında tek eksenli çekme testleri yapılarak malzemenin mekanik özellikleri belirlenmiştir. Sonlu elemanlar yöntemi kullanılarak sac malzemelerin farklı deformasyon hızlarında derin çekme analizleri gerçekleştirilmiş̧ir. Analizler sonucunda, deformasyon hızındaki artışın, ürünün üst kısımlarında et kalınlığında, incelmeleri artırdığı, etek kısımlarda kalınlık artışına yol açtığı, geri esneme miktarı ve kalıplama kuvvetini artırdığı belirlenmiştir.

Anahtar Kelimeler: Deformasyon hızı, Derin çekme, DP600 ve DP780 sac malzeme

\section{INVESTIGATION OF THE EFFECTS OF DEFORMATION SPEED ON THE MECHANICAL PROPERTIES AND DEEP DRAWING PROCESS OF DP600 AND DP780 SHEET METAL}

\begin{abstract}
In this study, the effects of deformation speed on the deep drawing process were investigated for DP600 and DP780 sheet materials that are widely preferred in the automotive industry. For this purpose, the uniaxial tensile tests were performed at the different deformation speeds to determine mechanical properties of materials. Deep drawing analyzes were carried out at different deformation speed by using finite element method. Analysis results show that the increase in the deformation speed cause to increase the amount of springback, forming force and the sheet thickness in the flanks while increasing thinning at upper area of the product are determined.
\end{abstract}

Key words: Deformation speed, Deep drawing, DP600 and DP780 sheet material

\section{GİRIŞ (INTRODUCTION)}

Günümüzde çift fazlı yüksek mukavemetli saclarının kullanımı oldukça yaygınlaşmışıır. Özellikle otomotiv sektöründe, çift fazlı (DP) olarak adlandırılan gelişmiş yüksek mukavemetli saclar, araç ağırlıklarını azaltarak yakın tüketimini düşürmekte ve dolayısıyla egzoz gazı emisyonunun azalmasina katkı sağlamaktadır. Ayrıca, yüksek mukavemet sağlaması ve yolcu güvenliğini arttırdığı için otomotiv endüstrisi tarafindan tercih edilmektedir [1-2]. Çift fazlı çelikler, yüksek mukavemetli düşük alaşımlı çelikler ile karşılaştırıldığında daha yüksek mukavemete, pekleşme oranına, enerji abzorbe edebilme yeteneğine ve daha düşük akma dayanımına sahip olması dolayısıyla kolay şekil alabilmektedirler [3].

Çift fazlı çelikler yumuşak ferrit ve sert martensit içeren düşük karbonlu çeliklerdir. Yapısında bulunan ferrit ve martensit fazları nedeniyle, çift fazlı çelik olarak adlandırılmaktadır. Çift fazlı çeliklerin isıl işlemi $\alpha+\gamma$ bölgelerine 1sttıldıktan sonra östenit yapının martesit yapıya dönüşebilmesi için hızlı soğutma ile tamamlanmaktadır. Soğutma sırasında malzemede oluşan martezit fazı çeliğin mukavemetini 
belirlemekte, yumuşak ferrit fazı ise sünekliği sağlamaktadır [4-5].

Yapılan çalışmada, sac şekillendirme işlemlerinde en çok tercih edilen yöntemlerden biri olan derin çekme metodu kullanılmıştır. Derin çekme metodu başta otomotiv sektörü olmak üzere imalat sektörünün birçok alanında sac parçaların şekillendirilmeside kullanılmaktadır. Derin çekme kalıplarında şekillendirilebilirliği, sac malzemenin özellikleri, yağlama şartları, zımba ve kalıp radyüsü ve baskı plakası basıncı, şekillendirme hızı ve sıcaklık gibi birçok farklı parametre etkilemektedir [6]. Kalıpçılık yöntemleri ampirik metotlara dayalı, deneysel çalışmaları gerektiren yüksek maliyetli yöntemlerdir. $\mathrm{Bu}$ nedenle, üretilmesi planlanan parça ve kullanılacak kalıbın işlem parametrelerinin önceden belirlenmesi maliyet ve zaman tasarrufu sağlamaktadır [7]. Son yıllarda, sac şekillendirme işlemleri öncesinde, sonlu elemanlar yöntemiyle çalışan analiz programları yardımıyla şekillendirme işleminde çalışma parametreleri optimizasyonu ile son ürün geometrisi benzetimi yapılarak en uygun şekillendirme gerçekleştirilebilmektedir [8].

Sac malzemelerin davranışları deformasyon hızı değişiminden etkilenmektedir. $\mathrm{Yu}$ ve arkadaşları DP600 sac malzemenin farklı deformasyon oranlarında davranışını incelemişlerdir. Sonuç olarak artan deformasyon oranının akma ve çekme mukavemetini arttığını tespit etmişlerdir [9]. Kim ve diğerleri çalışmlarında 3 farklı yüksek mukavemetli sac malzemeye farklı deformasyon oranlarında çekme testleri yaparak mekanik özelliklerini incelemişlerdir. Sonuç olarak akma dayanımı, çekme dayanımı ve toplam uzamanın arttığı görülmüştür [10]. Derin çekme işlemi, sac malzemede çekme zımbasının yan duvar ve flanş bölgesine kuvveti iletmesi ve bir merkeze doğru düzlemsel gerilmeler oluşturarak sacın kalıp boşluğu içerine aktarılmasıyla gerçekleştirilmektedir [6]. Derin çekmeyi etkileyen faktörler hakkında birçok çalışma yapılmıştır. Palumbo ve arkadaşları yaptı̆̆ı çalışmada, sac malzemenin farklı sicaklık ve hızlarda derin çekilebilirliği incelerek artan şekillendirme hızının şekillendirme sürecini olumsuz etkilediği belirtmişlerdir [11]. Lee ve diğerli yapyıkları çalışmada farklı deformsyon hızlarında çekme testleri yaprak sac malzemenin mekanik özelliklerini belirleyerek derin çekme analizleri yapmışlardır. Artan deformasyon hızının derin çekmede olumsuz sonuçlar verdiği bildirmişlerdir [12]. Tari ve arkadaşları çalışmalarında işlemini farklı sıcaklı ve hızların derin çekmeye etkilerini incelemişlerdir. Artan deformasyon hızının şekillendirme kuvvetini arttırdığı belirtmişlerdir [13]. Çavuşoğlu hazırlamış olduğu yüksek lisans tezinde farklı deformasyon hızlarının derin çekme işlemine etkilerini incelemiştir.
Deformasyon hızının artmasıyla geri esneme ve kalıplama kuvvetinin arttığını belirlemiştir [14].

Yapılan bu çalışmalarda, deformasyon oranı bağlı olarak malzemenin şekillendirilebilirliğinin etkilendiği dolayısıyla şekillendirme hızındaki değişiminle elde edilen ürün geometrisini etkileyeceğini göstermektedir [9-14].

Deformasyon hızı, malzemenin mekanik özellkleri ve ürünün et kalınlığındaki değişimleri, geri esneme miktarlarını ve şekillendirme kuvvetini doğrudan etkilemektedir. Bundan dolayı, kullanılan malzeme, şekillendirme şartları ve ürün geometrisine bağlı olarak en uygun şekillendirme hızının seçilmesi büyük önem taşımaktadır. Yapılan bu çalışmada, deformasyon hızının malzemenin mekanik özelliklerine veşekillendirme kuvvetleri üzerindeki etkilerinin incelenmesi amaciyla 4 farklı deformasyon hizında (7,5 mm/dak, $75 \mathrm{~mm} / \mathrm{dak}, 225 \mathrm{~mm} / \mathrm{dak}, 450$ $\mathrm{mm} /$ dak) çekme testleri yapılmıştır. Ayrıca, aynı hızlarda derin çekme analizleri yapılarak, deformasyon hızının malzemenin mekanik özelliklerine ve derin çekilebilirliğne etkileri incelenmiştir.

\section{MALZEME VE METOT (MATERIAL AND METHOD)}

\subsection{Materyal (Material)}

$\mathrm{Bu}$ çalışmada, otomotiv sektöründe kullanılan geliştirilmiş yüksek mukavemetli DP600 ve DP780 sac malzemeler kullanılmıştır. Deneysel çalışmalarda kullanılan sac malzemelerin kimyasal bileşimleri Tablo 1'de verilmiştir.

Tablo 1. DP600 ve DP780 sac malzemenin kimyasal bileşimi(Ağırlık \%) (Chemical composition of DP600 and DP780 sheet material(Weight \%))

\begin{tabular}{cccccc} 
Çelik Kalitesi & $\mathrm{C}$ & $\mathrm{Mn}$ & $\mathrm{Mo}$ & $\mathrm{Cr}$ & $\mathrm{Si}$ \\
\hline DP600 & 0,100 & 1,523 & 0,196 & 0,197 & 0,157 \\
\hline DP780 & 0,113 & 2,082 & 0,181 & 0,239 & 0,036 \\
\hline
\end{tabular}

Çekme testlerinin gerçekleştirilebilmesi için ASTME8 standartlarına uygun deney numuneleri hazırlanmıştır. Çekme testi numunelerinin ölçüleri Şekil 1'de verilmiştir. Çekme testi numuneleri su jeti ile kesilerek malzeme üzerinde oluşabilecek isıl etkilerin azaltılması sağlanmıştır. Ayrıca, numunelerin çekme testi sırasında çentik etkisi göstermemesi için yan yüzeyleri parlatılmıştır. 


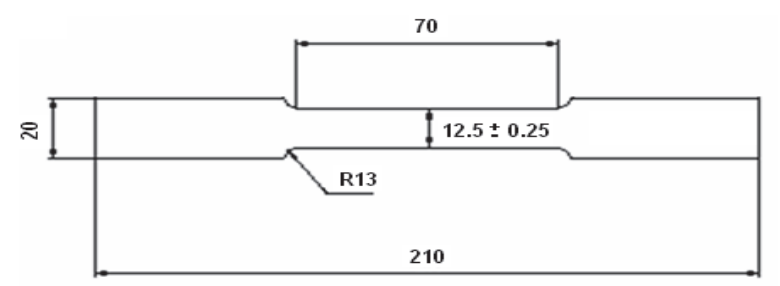

Şekil 1. ASTM E8 çekme testi numunesi (ASTM E8 standard tensile test specimens)

\subsection{Metot (Method)}

Çekme testleri, Zwick marka çekme test cihazında mekanik deformasyon ölçer ile gerçekleştirilmiştir. Çekme testleri üç farklı hadde yönü için $\left(0^{\circ}, 45^{\circ}, 90^{\circ}\right)$ $7,5 \mathrm{~mm} /$ dak, $75 \mathrm{~mm} /$ dak, $225 \mathrm{~mm} /$ dak ve $450 \mathrm{~mm} /$ dak deformasyon hızlarında yapılmıştır. Hata payını azaltmak için her bir sac malzeme türü ve her farklı deformasyon hızı için her test üç (3) defa tekrarlanarak ortalaması alınmıştır. Çekme testleri ile farklı deformasyon hızlarında gerçek gerilme - gerçek deformasyon eğrileri elde edilmiş ve veriler işlenerek sac malzemelerin farklı deformasyon hızlarındaki akma dayanımı, çekme dayanımı ve toplam uzama miktarları belirlenmiştir. Ayrıca, bilgisayar destekli şekillendirme analizlerinde ise gerçek gerilme gerçek deformasyon eğrilerinin sonlu elemanlar programına tanıtılması yardımıyla kullanılan sac malzemeler için farklı deformasyon hızlarında derin çekme analizleri yapılmıştır. Böylece, DP600 ve DP780 sac malzemeler için deformasyon hızının derin çekme işlemine etkileri belirlenmiştir.

\section{DENEYSEL SONUÇLAR VE TARTIŞMA (RESULTS AND DISCUSSION)}

\section{1. Çekme Testi (Tensile Test)}

Deformasyon hızının malzeme üzerindeki etkilerini incelemek için dört farklı deformasyon hızında (7,5 $\mathrm{mm} /$ dak, $75 \mathrm{~mm} / \mathrm{dak}, 225 \mathrm{~mm} /$ dak ve $450 \mathrm{~mm} / \mathrm{dak}$ ) çekme testleri yapılarak akma dayanımı, çekme dayanımı ve meydana gelen uzama miktarları Tablo 2'de verilmiştir.

Tablo 2. DP600 ve DP780 sac malzeme çekme testi sonuçları (Tensile test results of DP600 and DP780 sheet material)

\begin{tabular}{ccccc} 
Malzeme & $\begin{array}{c}\text { Deformasyon } \\
\text { Hız1 } \\
(\mathrm{mm} / \mathrm{dak})\end{array}$ & $\begin{array}{c}\text { Akma } \\
\text { Dayanımı } \\
(\mathrm{MPa})\end{array}$ & $\begin{array}{c}\text { Çekme } \\
\text { Dayanımı } 1 \\
(\mathrm{MPa})\end{array}$ & $\begin{array}{c}\text { Uzama } \\
(\%)\end{array}$ \\
\hline \multirow{6}{*}{ DP600 } & 7,5 & 409,77 & 734,75 & 15,3 \\
& 75 & 417,98 & 749,58 & 15,15 \\
& 225 & 418,12 & 755,63 & 15,7 \\
& 450 & 420,66 & 778,53 & 17,4 \\
\hline \multirow{5}{*}{ DP780 } & 7,5 & 518,68 & 827,46 & 7,3 \\
& 75 & 541,19 & 902,24 & 9,6 \\
& 225 & 543,16 & 911,46 & 9,9 \\
& 450 & 546,67 & 926,48 & 10,95 \\
\hline
\end{tabular}

DP600 ve DP780 malzemelerin çekme testinden elde edilen akma dayanımı değerlerinin deformasyon hızındaki değişimi ile ilişkisi Şekil 2'de verilmiştir. Akma dayanımı deformasyon hızına bağlı olarak yükselmektedir [15]. Grafikler incelendiğinde her iki malzeme içinde deformasyon hızı artışının akma dayanımı arttırdığı belirlenmiştir.

Deformasyon hızı artışında akma dayanımının yükselmesine bağlı olarak çekme dayanımı da yükselmektedir [15]. Malzemenin deformasyon hızına karşı davranışını incelemek amacıyla yapılan çekme testi sonuçları incelendiğinde deformasyon hızı artışının çekme dayanımını da $\operatorname{arttırdığı~tespit~}$ edilmiştir. Şekil 3'te çekme dayanımı - şekil değiştirme hızı ilişkisi verilmiştir.

Farklı şekillendirme hızlarında DP600 ve DP780 sac malzeme için elde edilen uzama değerleri Şekil 4'te verilmiştir. Şekil 4'te verilen sonuçlar incelendiğinde DP600 malzemenin DP780 malzemeye göre uzama değerlerinin yüksek olduğu açıkça görülmektedir. Bu da çift fazlı çeliklerde mukavemet değeri artışının yüzde uzamayı azalttığını göstermektedir. Ayrıca, deformasyon hızındaki artış malzemede büzülmeyi geciktireceğinden dolayı kopmadan önceki uzama miktarını arttırmaktadır [15]. Her iki malzeme için de deformasyon hızı arttığında yüzde uzama miktarı artmaktadır. Ancak, DP780 malzemenin DP600 malzemeye daha yüksek mukavemete sahip olduğundan dolayı deformasyon hızı artışından daha fazla etkilendiği düşünülmektedir.

Deformasyon hızının, akma dayanımı, çekme dayanımı ve toplam uzama ile olan ilişkileri incelendiğinde, literatürde yapılan [10] ve [11] nolu referanslarda belirtilen çalışmalarda elde edilen bulgular ile uyumlu bulunmuştur.

\subsection{Derin Çekme Analizleri (Deep Drawing Analyzes)}

Derin çekme analizleri sac metal parça üretiminde sıkça uygulanan bir işlemdir. $\mathrm{Bu}$ çalışmada 4 farklı şekillendirme hızında, DP600 ve DP780 sac malzemelere bilgisayar ortamında tasarlanan kalıp modeli için derin çekme analizleri yapılmıştır. Derin çekme analizlerinde kullanılan kalıp sistemi Şekil 5'te verilmiştir. Analizi sonuçları üzerinde noktasal ölçümler yapılarak gerçek şekillendirme işlemlerinde malzemede meydana gelebilecek olası sonuçlar öngörülmeye çalışılmıştır. Şekillendirme analizleri uygulanan model üzerinden ölçüm noktaları Şekil 6'da verilmiştir. Öncelikle, gerçek üretimde ürün kalitesinin değerlendirmesinde göz önünde bulundurulan sac kalınlığı ve geri esneme sonuçları incelenmiştir. Ayrıca, farklı şekillendirme hızlarında iki malzeme için de şekillendirme kuvvetleri belirlenmiştir. 


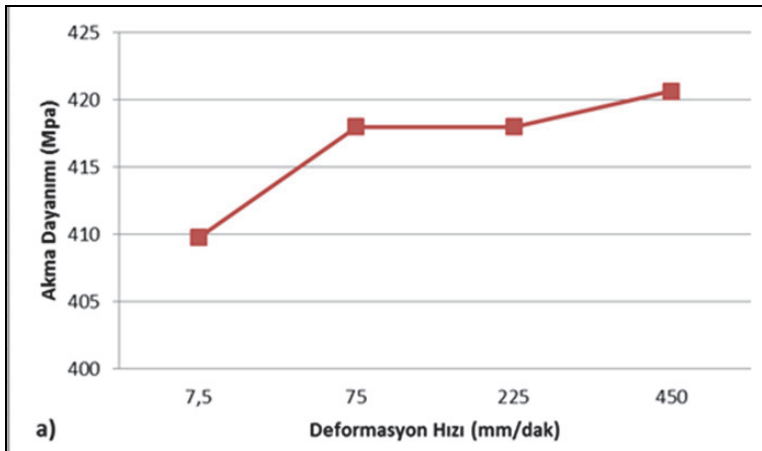

2.a) DP600

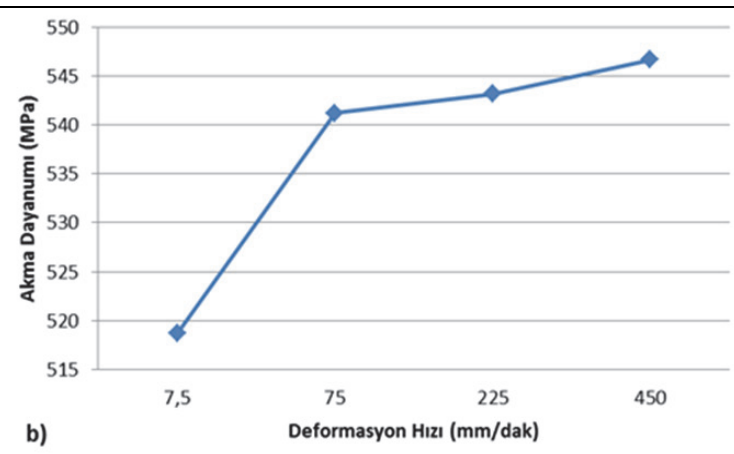

2.b) DP780

Şekil 2. Deformasyon hızı - akma dayanımı ilişkisi (Deformation speed - yield strength relation)

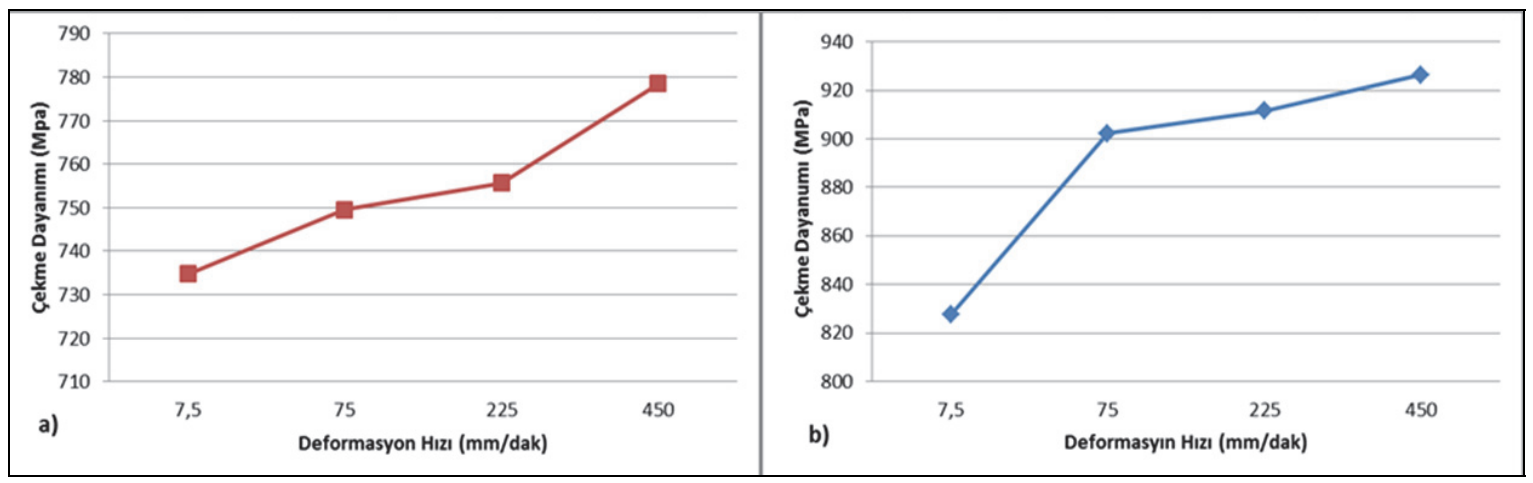

3.a) DP600

3.b) DP780

Şekil 3. Deformasyon hızı - çekme dayanımı ilişkisi (Deformation speed - tensile strength relation)

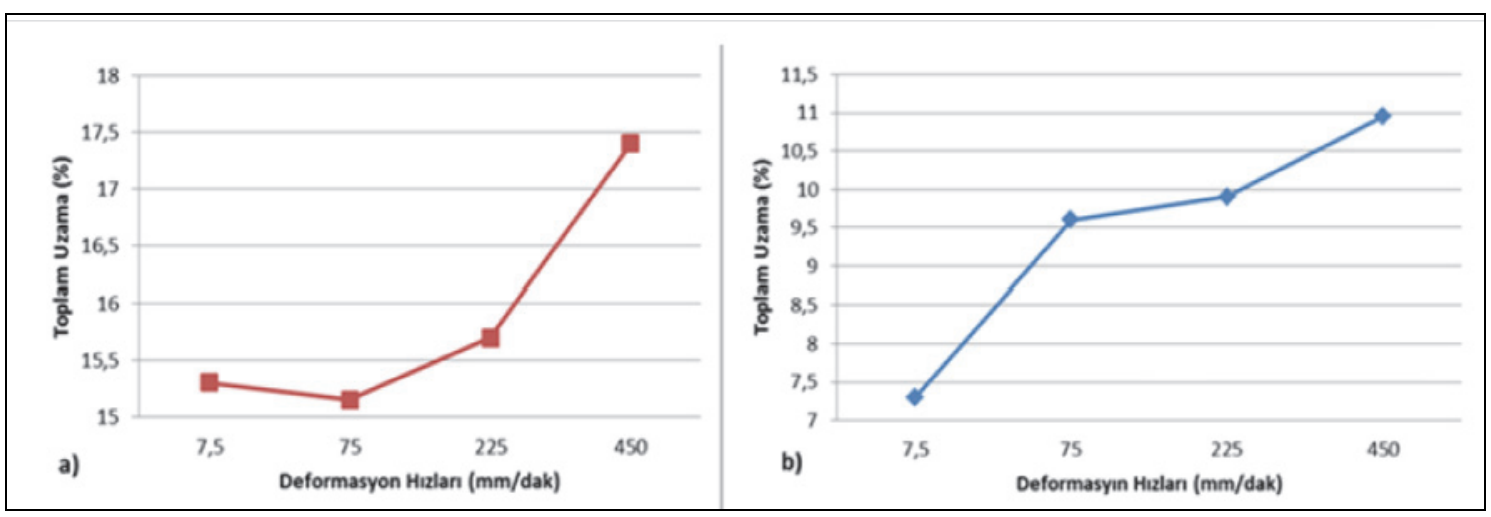

4.a) DP600

4.b) DP780

Şekil 4. Deformasyon hızı - \% uzama ilişkisi (Deformation speed - \% elongation relation)

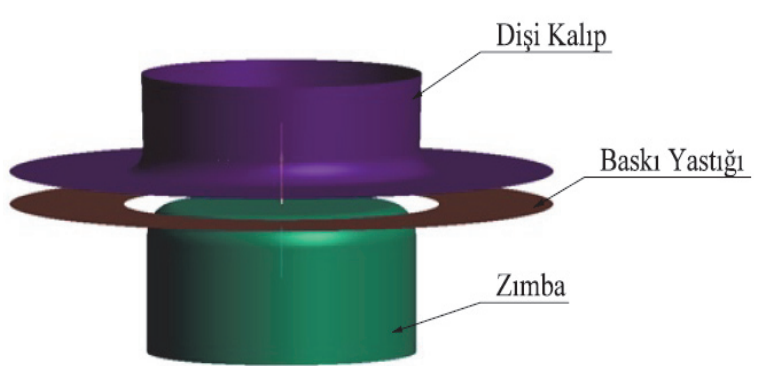

Şekil 5. Kalıp Modeli (Die Model)

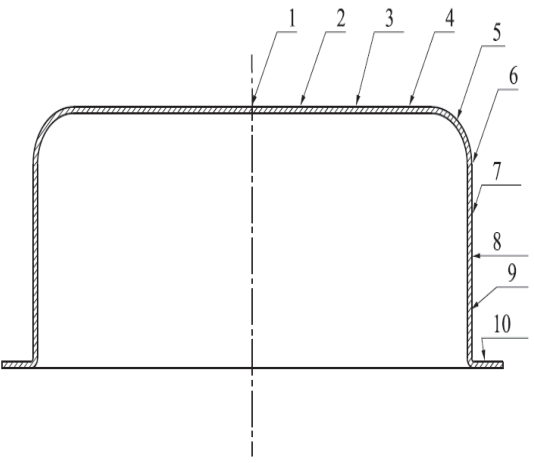

Şekil 6. Ölçüm Noktaları (Measurement Points) 


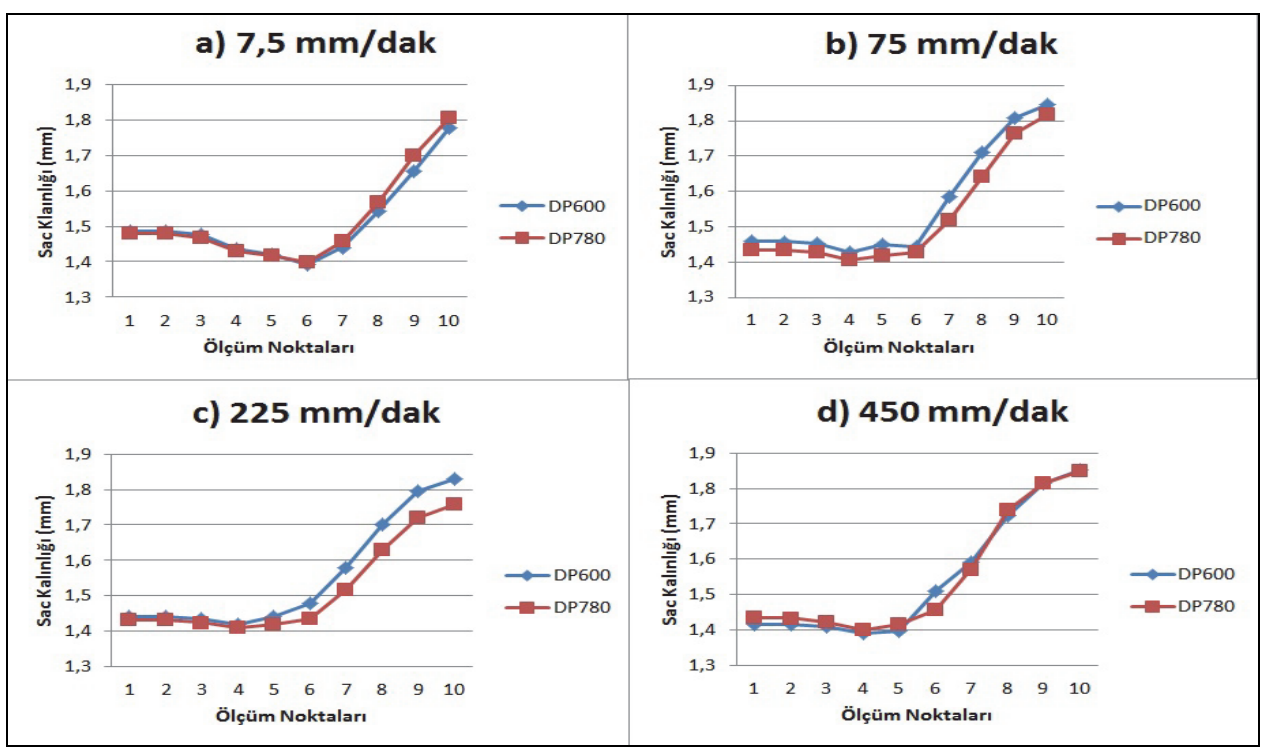

Şekil 7. Deformasyon hızı - sac kalınlığı değişim ilişkisi (Deformation speed - sheet thickness relation)

Farklı deformasyon hızlarında şekil verilen ürünlerin eksene dik kesitleri alınarak 10 farklı noktadan et kalınlığı değişimleri gözlenmiştir. Yapılan analizler sonucu elde edilen sonuçlar incelendiğinde (Şekil 7) şekillendirme hızının artması ile, ürünün dip kısmında, zımba kavisi bölgesinde ve çekilen kabın yan yüzeylerinde et kalınlıklarının azaldığı görülmektedir.

Analiz sonuçlarından et kalınlığındaki azalmanın en fazla zımba kavisinin olduğu bölgede ve çekilen ürünün yan duvarlarında gerçekleştiği belirlenmiştir. Ürün alt kavisi ve ürünün etek kısımlarında ise, artan şekillendirme hızlarına bağlı olarak et kalınlıklarında artış olduğu görülmektedir. Deformasyon hızına bağlı olarak elde edilen et kalınlığı sonuçlarından, DP600 ve DP780 malzemelerin her ikisinde de şekillendirme hızının artması nedeniyle ürünün alt kavisi ve etek kısımlarına daha fazla malzeme akışı gerçekleştiğinden dolayı bu bölgelerde et kalınlığının artmaşı ve malzeme yığılması oluşmaktadır. $\mathrm{Bu}$ nedenle, kırışıklık riskinin arttığı anlaşılmaktadır (Şekil 8 ve Şekil 9).

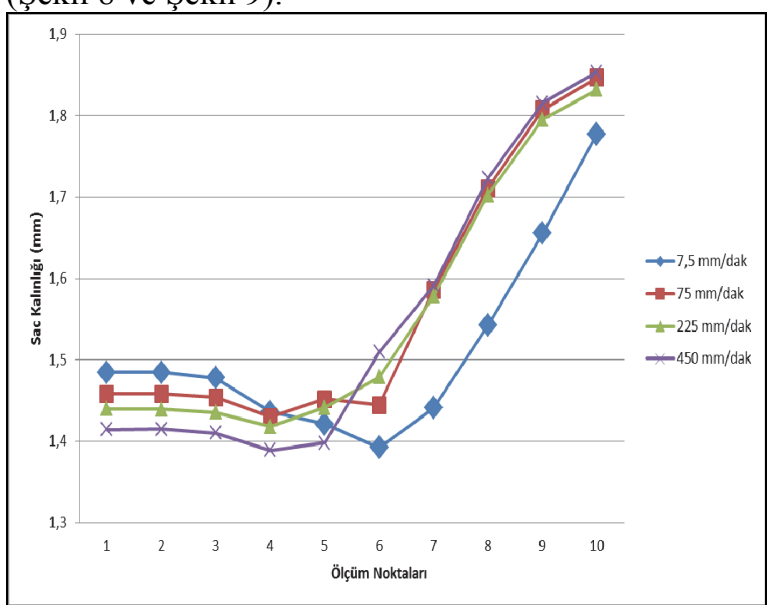

Şekil 8. DP600 deformasyon hızı - sac kalınlığ değişim ilişkisi (Deformation speed - sheet thickness relation for DP600)

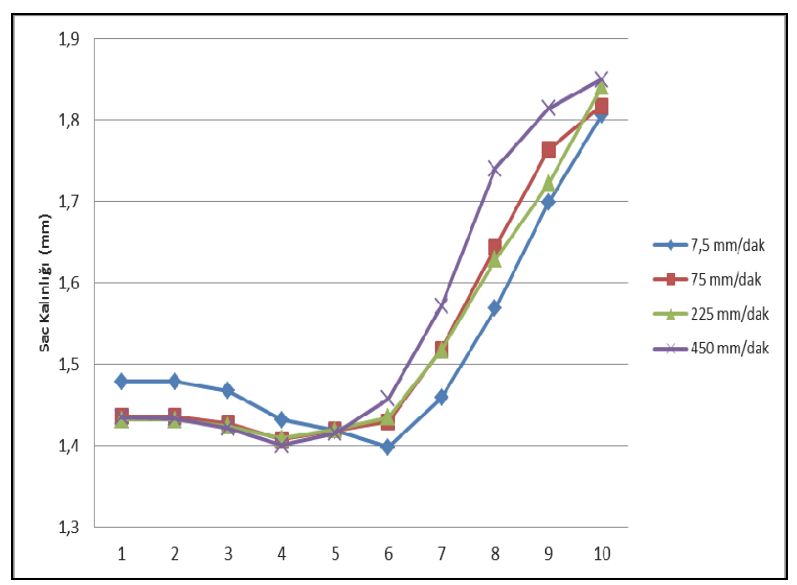

Şekil 9. DP780 deformasyon hızı sac kalınlığ değişim ilişkisi (Deformation speed - sheet thickness relation for DP780)

Sac metal şekillendirme işlemlerinin elde edilen ürün geometrisinin boyutsal toleranslar içinde olması istenmektedir. Ancak, sac kalıpçılığı incelendiğinde şekillendirme işlemlerinde karşılaşan en büyük sorunun kalıptan çıkan şekillendirilmiş parçada esnemeye bağlı boyutsal hatalar olduğu bilinmektedir [16].

Analiz sonuçlarında elde edilen verilen incelendiğinde her iki malzeme içinde deformasyon hızı arttıkça geri esneme miktarının arttığı belirlenmiştir. Ayrıca, derin çekme işlemi uygulanan model değerlendirildiğinde, sacın büküm noktasındaki geri esnemenin çok az miktarlarda olduğu, eteklerde ise şekillendirme işleminin sonunda sacın baskı plakasından kurtulması nedeniyle artı yönde yüksek miktarda esneme olduğu görülmektedir. Şekil değişimin daha az miktarda gerçekleştiği üst yüzey bölgesi incelendiğinde ise en düşük hız haricindeki diğer hızlarda, negatif yönde esneme meydana geldiği belirlenmiştir. En düşük hız değeri olan 7,5 mm/dak'da ise her iki malzemenin de üst yüzey bölgesinde positif esneme meydana gelerek 
farklı bir eğilim göstermiştir. Endüşük hız değerinde elde edilen bu pozitif esnemenin şekillendirme hızına bağlı olarak malzeme üzerinde deformasyon için gerekli zamanın sağlanmasından dolayı gerçekleştiği düşünülmektedir. DP600 ve DP780 sac malzemelerin farklı hızlarda gerçekleştirilen derin çekme işleminde oluşan esneme miktarları benzetim programıla tahmin edilmeye çalışılmıştır ve elde edilen değerler grafikler halinde Şekil 10, Şekil 11 ve Şekil 12'de verilmiştir.

Derin çekme analizlerinden DP600 ve DP780 için elde edilen şekillendirme süreci - kuvvet ilişkisi (Şekil 13 ve Şekil 14) incelendiğinde, deformasyon hızı artışına bağlı olarak şekillendirme kuvvetinin de arttığı belirlenmiştir. Literatürde, Tari ve arkadaşları ile Çavuşoğlu'nun yaptığı çalımalar ile uyumlu sonuçlar elde edilmiştir [13-14]. DP780 malzemede hıza bağlı olarak en yüksek kalıplama kuvveti değeri $390860 \mathrm{~N}$ olurken DP600 malzemede $335080 \mathrm{~N}$ değerinde olduğu görülmektedir.

Kuvvet grafiklerinin üst noktasında, kullanılan malzeme, malzeme kalınlığı ve şekillendirilecek form yapısına bağlı olarak en yüksek şekillendirme kuvveti oluşmaktadır. Sac malzemenin kalıp içerisine akması ile baskı kuvveti ve form verilecek parça alanının azalmasından dolayı şekillendirme kuvvetinin zamana bağlı olarak azaldığı görülmektedir. Form verme işleminin sonunda ise, küçük bir tepe oluşmaktadır. $\mathrm{Bu}$ küçük tepe noktasının, çekme derinliğine bağlı olarak oluşan ve çekme işleminin sonuna doğru zımba kavisinin ölçüsüne bağlı olarak sac malzemenin baskı plakasından kurtulması sonucu, baskı kuvvetinin ortadan kalkmasıyla oluşan malzemedeki düzensiz akışlardan kaynaklandığı düşünülmektedir.

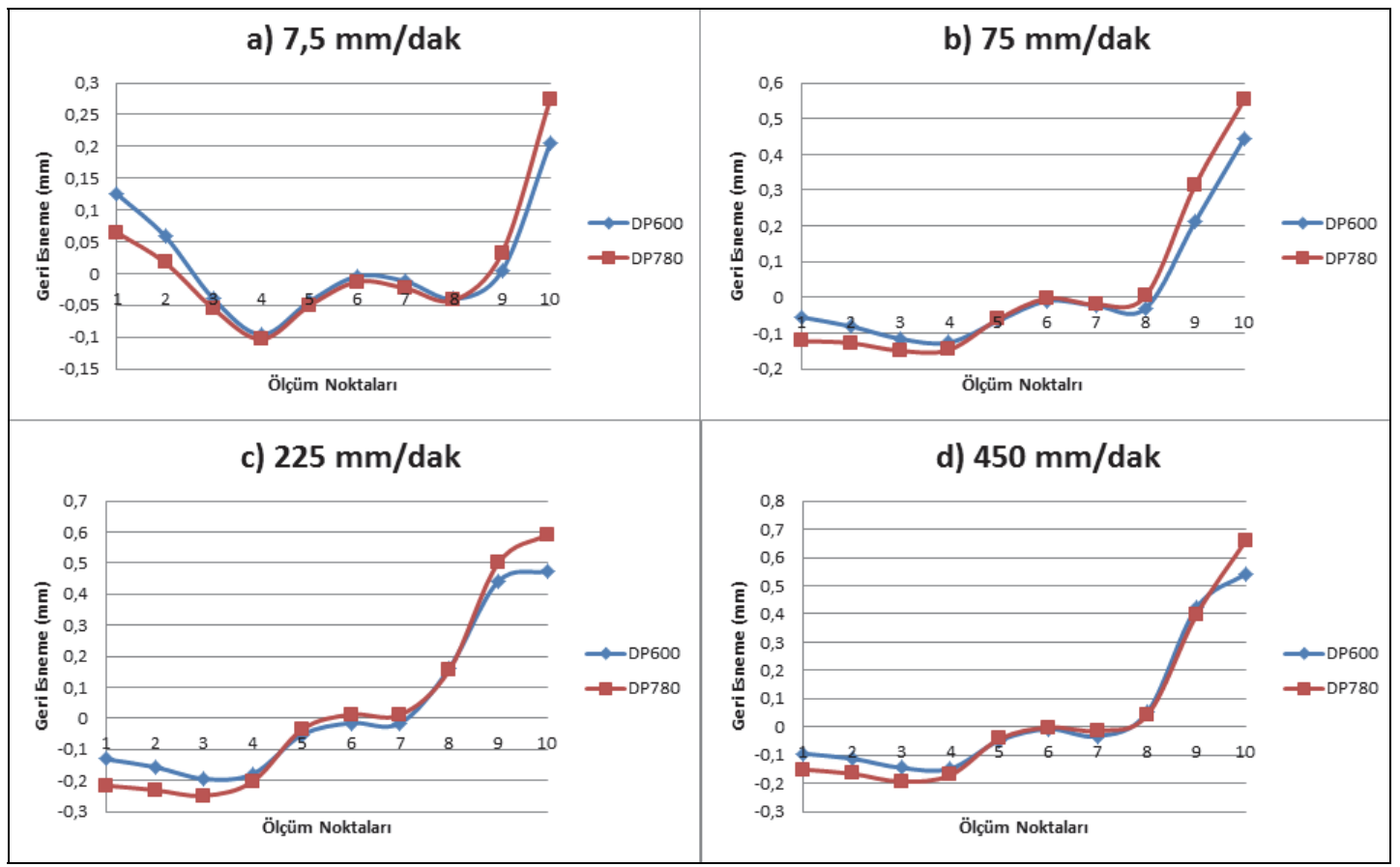

Şekil 10. Deformasyon hızı - geri esneme ilişkisi (Deformation speed - springback relation)

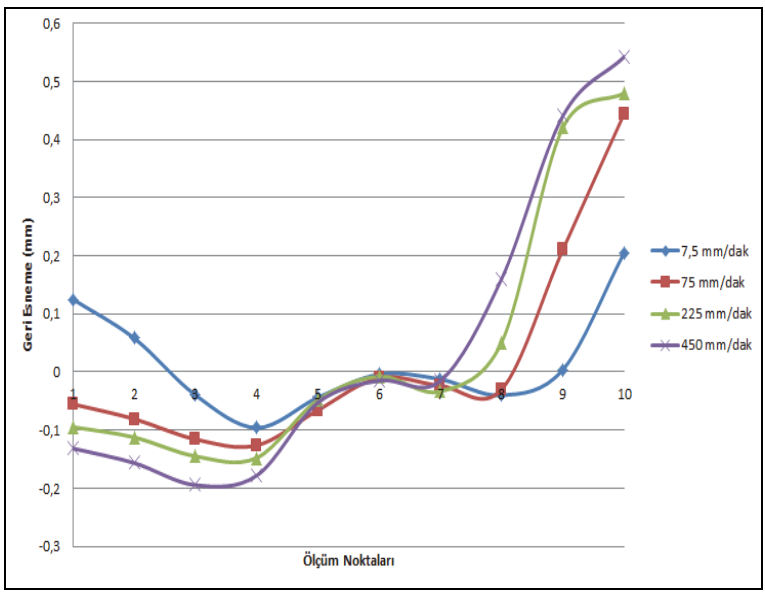

Şekil 11. DP600 deformasyon hız1 - geri esneme ilişkisi (Deformation speed - springback relation for DP600)

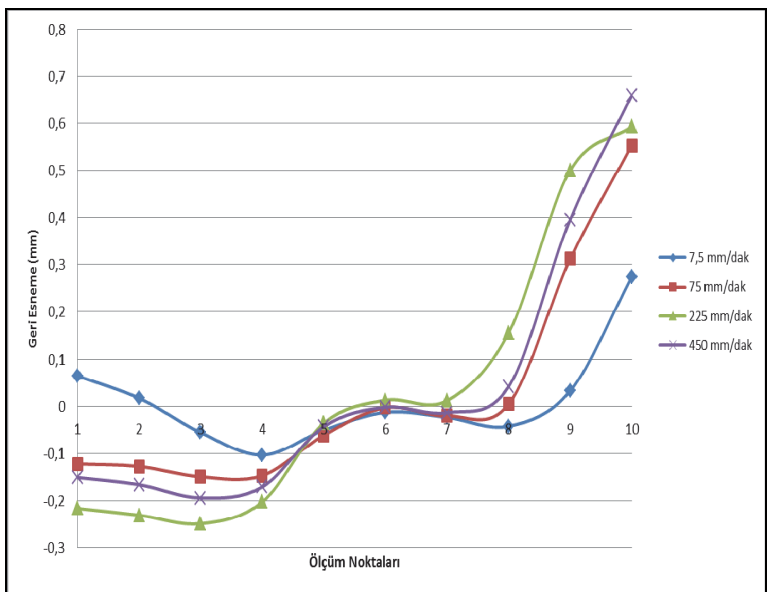

Şekil 12. DP780 deformasyon hızı-geri esneme ilişkisi (Deformation speed - springback relation for DP780) 


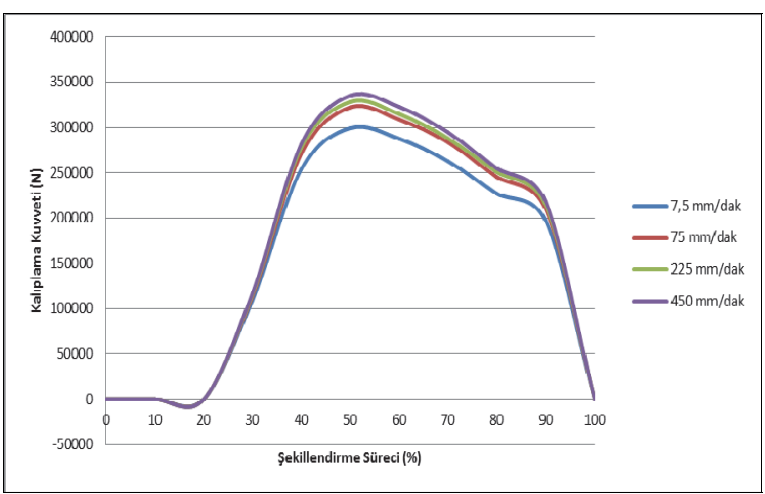

Şekil 13. DP600 deformasyon hız1 - şekillendirme kuvveti ilişkisi (Deformation speed - forming force relation for DP600)

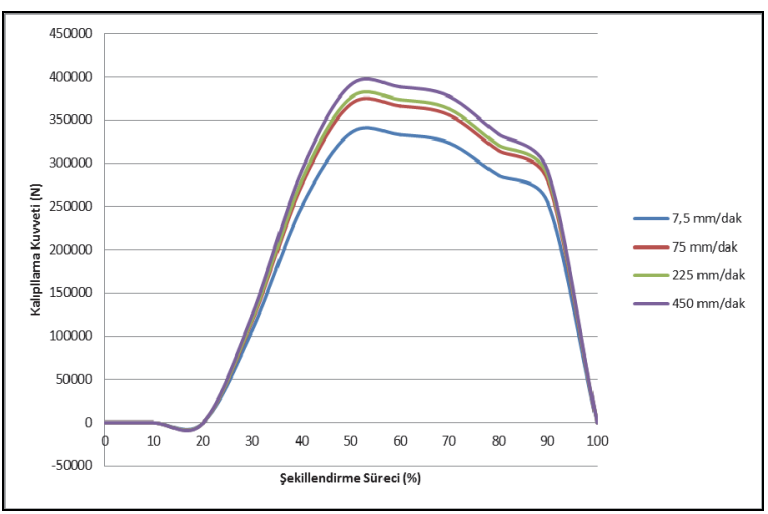

Şekil 14. DP780 deformasyon hızı - şekillendirme kuvveti ilişkisi (Deformation speed - forming force relation for DP780)

\section{SONUÇLAR (CONCLUSIONS)}

$\mathrm{Bu}$ çalışma ile elde edilen sonuçlar aşağıda özetlenmiştir.

- Deformasyon hızı arttıkça her iki malzemede de akma dayanımı, çekme dayanımı ve yüzde uzama miktarının arttığı belirlenmiştir.

- Farklı deformasyon hizlarında yapılan şekillendirme analizlerinden elde edilen sonuçlar incelendiğinde, deformasyon hızı arttıkça sacın etek kısımlarında kalınlaşma meydana geldiği, deformasyonun az olduğu üst bölgelerde ise genel olarak sacda hız artışıyla incelme meydana geldiği belirlenmiştir. DP780 sac malzemenin DP600 sac malzemeye göre daha yüksek mukavemete sahip olmasından dolayı, sac kalınlık dağılımları karşılaştırıldığında etek kısımlarında daha az kalınlaşma olduğu görülmüştür.

- Deformasyon hızı artışının esneme miktarını arttırdığ1 belirlenmiştir. Ancak, silindirik çekme işleminde en fazla deformasyonun meyana geldiğ $\mathrm{i}$ büküm noktalarında geri esnemenin çok az olduğu gözlemlenmiştir. Ayrıca, DP780 sac malzemenin DP600 sac malzemeye göre şekillendirme işlemi sonrasında daha fazla esneme davranışı gösterdiği belirlenmiştir.
- Yapilan analizler sonucunda, deformasyon hızındaki artışın şekillendirme kuvvetini arttırdığ belirlenmiştir. DP780 sac malzemenin DP600 sac malzemeye göre daha yüksek mukavemete sahip bir malzeme olmasından dolayı kalıplama kuvvetinin daha yüksek olduğu tespit edilmiştir.

\section{TEŞEKKÜR (ACKNOWLEDGEMENT)}

Bu çalışma, Gazi Üniversitesi, Bilimsel Araştırma Projeleri Birimi tarafindan 07/2010-25 kodlu proje kapsamında desteklenmiştir.

\section{KAYNAKLAR (REFERENCES)}

1. Wang, W., Wei, X., "The effect of martensite volume and distribution on shear fracture propagation of 600-1000 $\mathrm{MPa}$ dual phase sheet steels in the process of deep drawing", International Journal of Mechanical Sciences, 67, 100-107, 2013.

2. Ozturk, F., Toros, S., Kılıç, S., "Tensile and spring-back behavior of DP600 advanced high strength steel at warm temperatures", Journal of Iron and Steel Research. International, 16 (6), 41-46, 2009.

3. Zhang, H., Wei, A., Qui, J.C., "Microstructure and mechanical properties of resistance spot welded dissimilar thickness DP780/DP600 dualphase steel joints", Materials \& Design, 54, 443449, 2014,

4. Huh, H., Kim, S.B., Song, J.H, Lim, J.H., "Dynamic tensile characteristics of TRIP-type and DP-type steel sheets for an auto-body", International Journal of Mechanical Sciences, 50, 918-931, 2008.

5. Wu-rong, W., Chang-wei, H., Zhong-hua, Z., Xicheng, W., "The limit drawing ratio and formability prediction of advanced high strength dual-phase steels", Materials \& Design, 32, 6, 3320-3327, 2011.

6. Rahu, S., Ganesan, G., Karthikeyan, R., "Influence of variables in deep drawing of AA 6061 sheet", Trans. Nonferrous Met.Soc. China, 20, 1856-1862, 2010

7. Colgan, M., Monaghan, J., "Deep drawing process: analysis and experiment", Journal of Materials Processing Technology, 132, 35-41, 2003.

8. Yılız, H., Kırlı. O., Derin çekme işleminin doğrusal olmayan sonlu elemanlar metodu yardımıyla modellenmesi, Mühendislik Bilimleri Dergisi, 10 (3), 317-326, 2004.

9. Yu, H., Guo, Y., Lai, X., "Rate-dependent behavior and constitutive model of DP600 steel at strain rate from $10^{-4}$ to $10^{3} \mathrm{~s}^{-11}$, Materials and Design 30, 2501-2505, 2009.

10. Kim, J-H., Kim, D., Han H, N., Barlat, F., Lee, M-G., "Strain rate dependent tensile behavior of advanced high strength steels: Experiment and 
constitutive modeling", Materials Science \& Engineering, A 559, 222-231, 2013.

11. Palumbo, G., Sorgente, D., Tricarico, L., Zhang, S.H., Zheng,W.T., "Numerical and experimental investigations on the effect of the heating strategy and the punch speed on the warm deep drawing of magnesium alloy AZ31", Journal of Materials Processing Technology, 191, 342-346, 2007.

12. Lee, Y. S., Kwon, Y. N., Kang, S. H., Kim, S. W., Lee, J. H.," Forming limit of AZ31 alloy sheet and strain rate on warm sheet metal forming", Journal of Materials Processing Technology, 201, 431435, 2008.

13. Tari, D, G., Worswick, M, G., Winkler, S., "Experimental studies of deep drawing of AZ31B magnesium alloy sheet under various thermal conditions", Journal of Materials Processing Technology, 213, 1337-1347, 2013.

14. Çavuşoğlu, O., Sac Metal Şekillendirme İşlemlerinde Pres Hızı ve Malzemenin Şekillendirmeye Etkilerinin Deneysel ve Teorik Olarak İncelenmesi, Yüksek Lisans Tezi, Gazi Üniversitesi, Fen Bilimleri Enstitüsü, 2013.

15. Çapan, L. Metallere plastik şekil verme, Çağlayan kitapevi, İstanbul, 2010.

16. Lingbeek, R., Huetink, J., Ohnimus, S., Petzoldt, M., Weiher, J., "The development of a finite elements based springback compensation tool for sheet metal products", Journal of Materials Processing Technology, 169, 115-125, 2005. 